\title{
Understanding why marketing does not use the corporate data warehouse for CRM applications
}

Received: 15th January, 2003

\section{Fay Cobb Payton}

is an assistant professor of Information Systems at NC State University, where she researches how companies can use corporate data warehousing for competitive advantage and improve their data quality efforts. She holds a doctorate in information systems from Case Western Reserve University in Cleveland, Ohio. Prior to receiving her doctorate, she worked in the information systems area and currently consults with large companies regarding their database and data warehousing strategies.

\section{Debra Zahay}

is the Acxiom Professor of Interactive Marketing at Northern Illinois University in DeKalb, Illinois. She holds a doctorate in marketing from the University of Illinois in Urbana Champaign. She studies how companies can facilitate customer relationships. She has worked for various industrial firms in executive marketing positions, developing a specialty in business-to-business direct and database marketing and has been the president of her own relationship marketing consulting firm since 1993.

\begin{abstract}
This study uses a previously validated model to explore the experiences of one large regional US health care payer in its implementation of a corporate data warehouse to support the marketing function via customer relationship management (CRM) applications. The organisation invested significant time and other valuable resources on its data warehouse applications but perceived that the warehouse was underutilised by the marketing function. Current estimates indicate that as many as 50-70 per cent of CRM implementations have failed and the figures for data warehouse applications are not much better. Using a case study methodology and independent coders, the authors analysed transcripts from five focus group sessions that they conducted with 21 marketing, information systems and strategic managers at a large regional healthcare payer. Their findings suggest that the ability of marketing to use the system for its functional needs, various aspects of information quality and the internal training were factors that ranked highly in terms of significance to implementation success. In this case, the corporate data warehouse and associated interface often failed to meet users' expectations.
\end{abstract}

\section{INTRODUCTION AND RESEARCH QUESTION}

Debra Zahay Acxiom Professor of Interactive Marketing, College of Business, Northern Illinois University, DeKalb, IL 60015, USA.

Tel: +1 8157536215 ; Fax: +1 815753 6224; e-mail: zahay@niv.edu

\section{Corporate data needs expand}

The proliferation of data warehousing technologies and applications has been widely documented among information technology consultants and vendors. According to Gartner, ${ }^{1}$ organisations will be confronted with the challenge of managing 30 times more data by 2004 in a continual effort to meet the demands associated with electronic commerce and supply chain applications. Defined as a well-defined central repository used for decision support, data warehouses are subject oriented, time variant and non volatile. Data are collected over time and 
used to perform trend analyses, forecasting and comparative analyses. Typically, these data are not updated in real time. Rather, data are refreshed on a periodic basis from operational systems, as was the case with the company studied here. To enable these capabilities, data warehousing implementations can deploy multi, parallel and massive processing databases as well as a series of other hardware and software technologies. ${ }^{2}$

\section{CRM and data warehousing are costly and often fail}

Customer relationship management (CRM) applications as well as sales force automation (SFA) and contact management applications are often enabled by data warehousing technologies. These technologies offer significant research opportunities. Although there are many definitions of CRM, broadly defined, CRM is a process/application that permits organisations to gather and analyse customer data rapidly while seeking to improve customer retention and profitability via targeted products and services. ${ }^{3,4}$ A typical CRM

implementation is costly with researchers and practitioners alike documenting expenditures well over $\$ 1-2 \mathrm{~m}$ in year one and record spending in $2003 .^{5}$ In fact, IDC projected that the worldwide spending on CRM applications, including databases, would total $\$ 20 \mathrm{bn}$ by $2004 .{ }^{6}$ Compounding the widely reported CRM implementation failures ranging in rates of $55-75$ per cent ${ }^{7,8}$ is the fact that data warehouses have often been used as the underlying basis for CRM and add to the complexity of the applications.

In a study of 111 organisations, Wixon and Watson offered specific empirical findings affecting data warehousing implementations. ${ }^{9}$ While their study expanded the existing information systems implementation knowledge, the research did not focus specifically on CRM applications for the information in the data warehouse. While one qualitative study has focused on the data aspect of CRM implementation, ${ }^{10}$ few studies have investigated the implementation of data warehouses for the purposes of supporting marketing applications, such as CRM. Moreover, few studies have pointed out the relevance of data quality to the users of the data warehouse.

\section{Why is marketing not using the corporate data warehouse?}

When the authors were approached in the spring of 2001 by a large regional US healthcare payer with the general question, 'Why isn't our marketing function using our corporate data warehouse information and applications?' the authors had little empirical research on which to draw. They suggested a series of focus group interviews with functional marketing and information systems managers at the organisation which served as the basis for the case study. As a starting point for the research, they used an existing, validated model that looked at the factors leading to successful information technology implementations. This paper describes the model, the focus group process and presents the results of the study.

\section{THE RESEARCH QUESTION AND RESEARCH MODEL}

\section{What factors lead to implementation success?}

The authors restated the general question posed by the company to a question which could more specifically guide the 


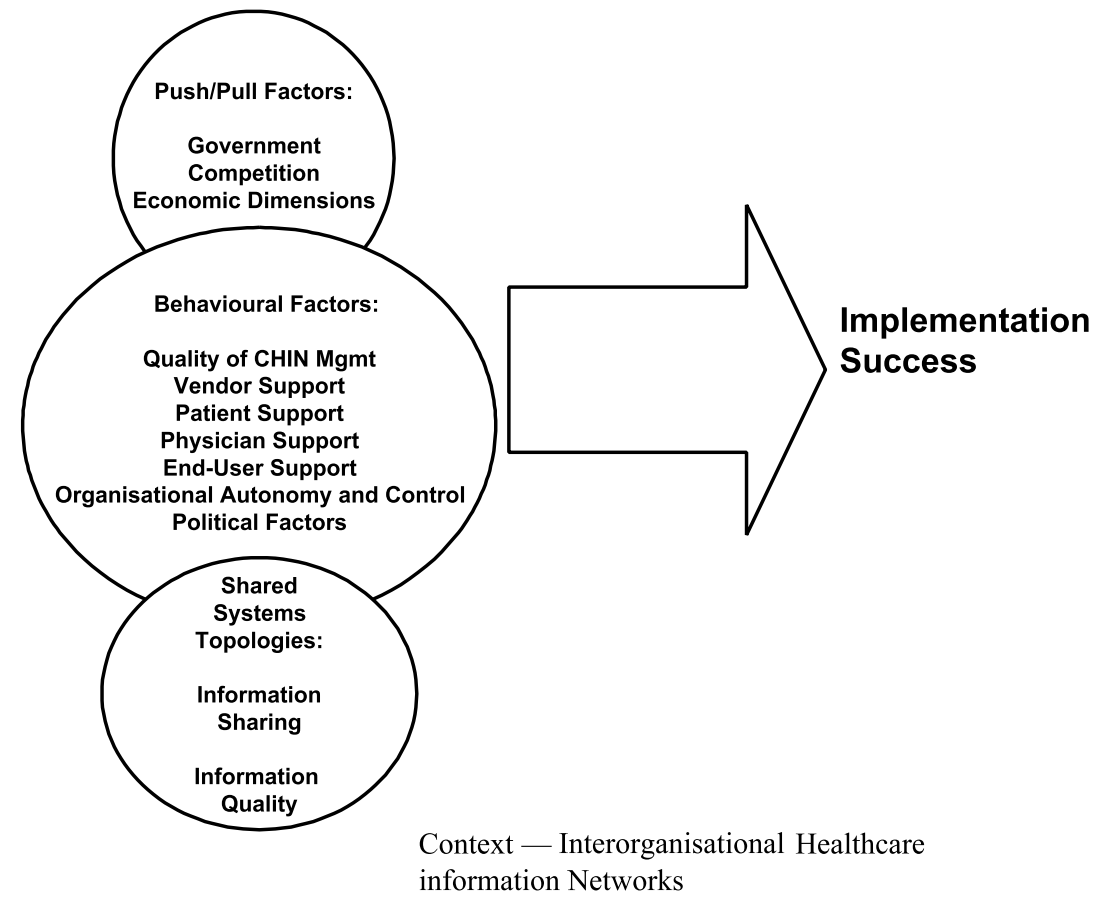

Figure 1: Implementation model by Payton and Ginzberg (2001)

research, that is, "What factors impact and/or stand to impact implementing our corporate data warehousing to support CRM applications for the marketing function?' After investigating the existing options, they adopted a model used by Payton and Ginzberg ${ }^{11}$ to explore the implementations of multiple health care information networks (Figure 1). Prior to the focus group interviews, they confirmed the relevance of the model to the particular organisation and the implementation in question through sharing with marketing, information technology and strategy managers the questions that guided the original model as published in Payton and Ginzberg.

In the original model, as shown in Figure 1, three factor clusters are defined: push/pull factors, behavioural factors and shared systems topologies. Push or pull factors are elements that can persuade an organisation's willingness to adopt a given technology, strategy, and/or change initiative. Behavioural factors are aspects that stand to affect and/or influence stakeholders including end-user support. Shared or integrated systems topologies represent certain aspects of the infrastructure needed for a data warehouse. These factors include arrangements for cooperation and information sharing as well as for assuring information quality.

\section{Adapting an existing implementation model}

Based on the initial discussions with management at the company the authors changed Figure 1 to eliminate factors not relevant to this situation. For example, government support was not relevant in this implementation since this was an intraorganisational effort not dependent on government funding. The resulting changes to the model are reflected on the left-hand side of Figure 2, which 


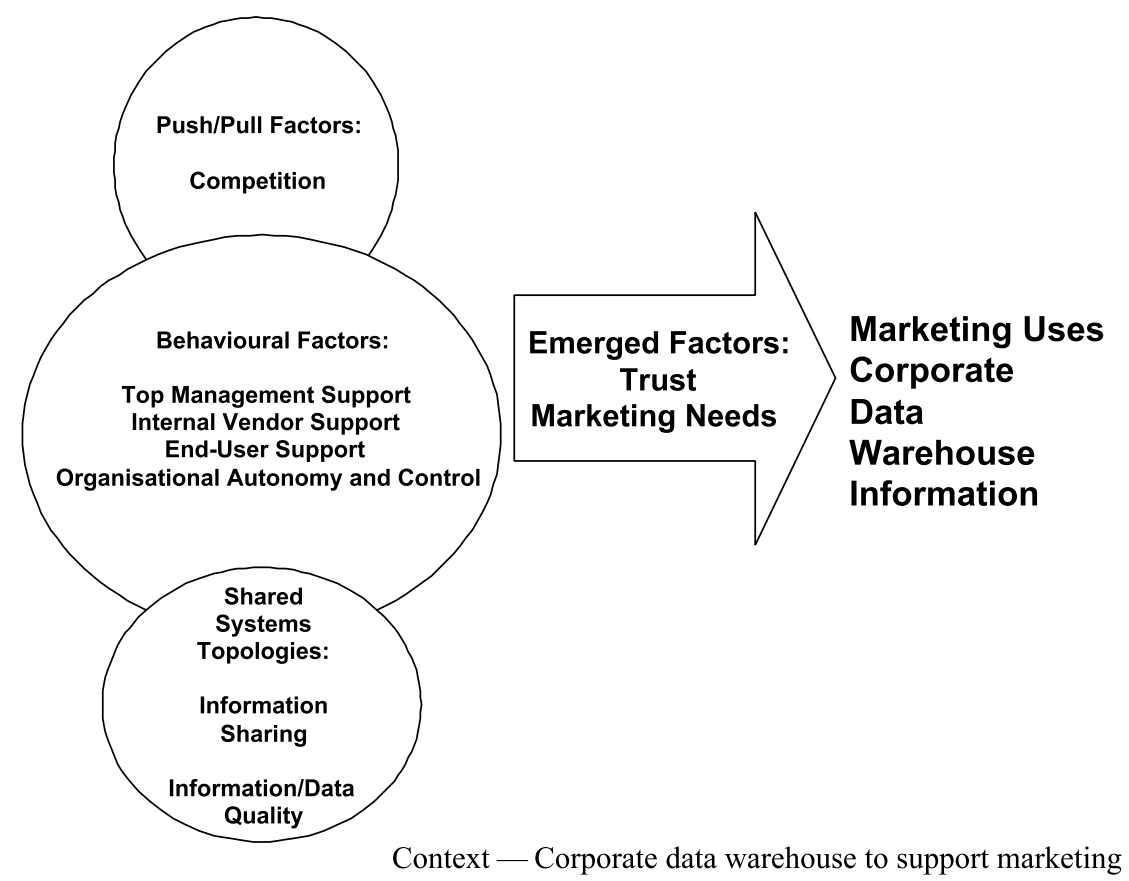

Figure 2: Model as specified in this study (2003)

shows a more streamlined set of implementation issues.

The dependent variable in this implementation model is the success of the implementation effort. The authors sought to explore the implementation of a data warehouse that was not deployed initially and exclusively for CRM and other marketing applications. Therefore, in this effort, the dependent variable in this model is success of the implementation effort, in terms of the use of the corporate data warehouse by marketing for its functional work. It is interesting that the authors did not add any specifically marketing-oriented questions to their focus group questions as adapted from the original work by Payton and Ginzberg and shown in Appendix 1 to obtain their data. The initial questions as adapted were broad enough to elicit responses to the larger question at hand, 'What factors impact and/or stand to impact implementing our corporate data warehousing to support
CRM applications for the marketing function at this organisation?'

\section{METHODOLOGY}

\section{Data collection}

Data were gathered from five two-hour focus group sessions with this single large healthcare payer group. Sessions were held almost exclusively with marketing and information technology teams and included current, forthcoming and power users, data warehousing internal systems staff and middle management. Note that some power users represented the finance department, since marketing personnel relied upon these users for help with their marketing queries and applications. Appendix 1 lists the questions that were asked of all focus group participants, as adopted from the prior implementation work of Payton and Ginzburg. Prior to using these questions in the focus group sessions, the authors pre-tested their 
Table 1: Summary of all coded items, ranked by frequency of mention

\begin{tabular}{|c|c|c|}
\hline Frequency & Coded item & Model category \\
\hline 99 & $\begin{array}{l}\text { Quality: Believability, completeness, timeliness, amount, ease of } \\
\text { understanding and accessibility }\end{array}$ & Data quality \\
\hline 76 & Ease of use of interface (aka quality accessibility) & Marketing needs \\
\hline 69 & Top management support & $\begin{array}{l}\text { Top management } \\
\text { support }\end{array}$ \\
\hline 64 & Ease of use of CDW itself (aka quality accessibility) & Marketing needs \\
\hline 57 & Marketing analysis needs & Marketing needs \\
\hline 51 & System provides accurate/right data & Data quality accuracy \\
\hline 49 & Standardisation of data definitions and structures & Data integration \\
\hline 38 & Training should be based on the actual users' roles, job tasks & Training \\
\hline 38 & Need other data in CDW (aka quality completeness) & Marketing needs \\
\hline 38 & Marketing needs not a priority & Marketing needs \\
\hline 34 & Systems used prior to current applications & Legacy systems \\
\hline 30 & Lack of trust in system (aka quality believability) & Marketing needs \\
\hline 29 & The training potential of users should be assessed & Training \\
\hline 29 & Legacy systems are vital data sources for CDW & Legacy systems \\
\hline 27 & Data dictionary needs (aka quality ease of understanding) & Marketing needs \\
\hline 25 & Determination of user requirements & Needs assessment \\
\hline 23 & External data needs (aka quality completeness) & Marketing needs \\
\hline 22 & Communication between group members, users and managers & Needs assessment \\
\hline 20 & Power users have functional jobs and also are gurus for CDW & Power users \\
\hline 18 & $\begin{array}{l}\text { Data that are fit to be used by data consumers (data quality } \\
\text { accuracy) }\end{array}$ & Data quality \\
\hline 16 & $\begin{array}{l}\text { Perceived management support with willingness to commit } \\
\text { resources }\end{array}$ & Needs assessment \\
\hline 13 & Tools used to educate users & Training \\
\hline 10 & $\begin{array}{l}\text { Users should be engaged in the training process from the } \\
\text { beginning }\end{array}$ & Training \\
\hline 9 & System supports functional elasticity & Flexibility \\
\hline 8 & The ability of CDW to contribute to perceived economic benefits & Economic impact \\
\hline 7 & Strength of management's message re: CDW & Needs assessment \\
\hline 6 & Where and how the CDW must evolve (system flexibility) & Flexibility \\
\hline 5 & Links architecture, planning, HR skills & Flexibility \\
\hline 5 & Implementing CDW is expensive but nevertheless useful & Economic impact \\
\hline 3 & Alternative system needs & Marketing needs \\
\hline 1 & Definitions agreed upon over time & Data integration \\
\hline
\end{tabular}

919 total statements, 462 per each of two coders

research model via five one-hour interviews, meeting notes and other fact-finding sessions with managers from the healthcare organisation. This pre-work enabled them to determine the validity and appropriateness of their constructs in the context of the organisation.

Top management agreed not to attend the focus group sessions to avoid biased responses to questions asked. The sessions were conducted over the summer of 2001. All focus group sessions were recorded and transcribed by a professional writer on the staff at the healthcare organisation as well as a member of the research team within 48 hours. Names and titles were withheld from all transcribed documents.

\section{Data analysis}

To analyse the focus group data, the authors adopted the analysis method prescribed by Yin. ${ }^{12}$ This method allows for re-examination of the data to see emerging patterns. They analysed the data in the transcripts themselves and then developed coding dictionaries to capture the marketing and information systems-related constructs. Their coding dictionaries can be found in Appendices 2 and 3. Two independent coders were then asked to categorise statements from 
the focus groups and the results were then combined to develop a content analysis based on frequency of mention.

\section{FINDINGS}

\section{Quality and marketing needs dominate}

The detailed results of the analysis of all five focus groups are reported in Appendices 2 and 3 and summarised in Table 1. As Table 1 indicates, the needs of marketing were most frequently mentioned as important to the participants and as preventing them from using the corporate data warehouse (CDW) application. The entire model was supported, but quality issues and needs of marketing dominated.

Marketing needs that can be linked to data quality issues, marketing needs, overall data quality issues and training were the most important factors in preventing the widespread adoption of the CDW in this organisation. These categories represent 66 per cent of the total 919 statements coded by the two independent coders. Thus the analysis that follows will focus on describing these categories in more detail. Again, more details on the coded statements are available in Appendices 2 and 3 .

Overall, users supported the idea of the warehouse and the benefits derived from the technology. The focus groups, however, indicated that marketing needs included specialised analysis that could not be performed with the present combination of warehouse data and analysis tools. These analyses were fairly standard data mining/database marketing types of applications, ${ }^{13-15}$ such as segment profile characteristics to target marketing programmes, longitudinal analysis and the comparison of customers who had purchased and those who had not. Apparently, these analyses had not been considered in detail prior to implementation, particularly the needs of marketing for historical data on lost customers and information about future prospects. As one frustrated focus group participant noted: "“What would you expect from (our) data warehouse?" I would say that you (are) either looking to do one of a few things. That is, decrease your costs, increase your membership - increase or retain your membership. We cannot do this or it takes a lot of work to meet our marketing needs.' (Marketing manager).

\section{The dimensions of quality}

Although the marketing has considered itself with the notion of quality of research reports ${ }^{16}$ and service experiences,${ }^{17}$ it is information systems studies which provide the most comprehensive assessment of data quality. In particular, Wang and Strong administered a two-stage survey to 25 industry consumers and $112 \mathrm{MBA}$ students to explore the scope of data quality. ${ }^{18}$ Some of the data quality dimensions identified were believability, completeness, timeliness, amount, ease of understanding and accessibility. In this study the authors instructed the data coders to include general quality statements in one category and also include a separate category for data accuracy, given that accuracy was identified separately and specifically by those in the focus groups. All mentions of quality totalled 18 per cent of total statements coded.

\section{Marketing needs dominate, relate to quality}

So many mentions were made of overall marketing needs that were not considered in implementation that considering marketing needs as a factor 
relating to implementation success was identified in the revised model in Figure 2. Overall, marketing needs accounted for 356 coded statements or 39 per cent of all statements. In addition, the general category of marketing needs included several categories which, after the initial analysis, appeared to be strongly related to overall data quality dimensions as delineated by Wang and Strong. ${ }^{19}$ These marketing needs which related to quality dimensions accounted for 28 per cent of total statements coded, meaning that quality related issues accounted for over 50 per cent of statements coded. As a focus group participant noted: 'All right, so we're using less than ideal ways of measuring the effectiveness of those things right now, I would say. Because we don't, I think, have the data or don't understand how to use the existing data (from the warehouse) well enough to be able to get at it. This is a matter of trusting this data and its quality to make major business decisions and we are not there, yet.' (Marketing manager).

Specifically, the users mentioned the ease of use of the interface as well as overall ease of use of the warehouse, which could also be considered as relating to the accessibility dimension of quality, ${ }^{20}$ so those needs were broken out separately and the coders were instructed to classify them according to how marketing needs related to dimensions of quality.

Another example is that users mentioned that they needed other data that were not in the warehouse, which relates to the completeness dimension of data quality. These needs were for external, demographic and descriptive data for the consumer market and Dun \& Bradstreet company descriptive data for the commercial (business-to-business,
B2B) applications which were missing from the data warehouse. Other missing data included information on former customers and prospective customers, neither of which are in the CDW. In addition, users expressed interest in a data dictionary, which relates to the perceived ease of understanding of the data. Users did not have an exact idea what data items meant and consequently could not use them.

Perhaps most importantly, users and potential users continue to distrust data extracted from the warehouse, which relates to the dimension of quality known as believability. ${ }^{21}$ Focus group participants reported 'reconciling' mainframe reports to the information from the data warehouse. In addition, overall quality issues were mentioned frequently, such as overall accuracy of the information and other dimensions of data quality.

\section{Training and the user interface}

In addition, marketers expected the interface to resemble that experienced in training or to be similar to other packages (eg SPSS) that they used in their work by capturing 'click and drag' features. In training, the queries were set up prior to the session and the users had an impression that the system would have a more 'canned' appearance than the system they eventually received. Participants were less likely to use what they perceived as more technically oriented reporting tools (eg business objects) and more likely to consult local 'power users' to get an answer to a query. These power users had become resident experts with the application and as a consequence were somewhat overworked in the organisation.

Finally, the issue of training was one of the most frequently mentioned, with users 
reporting that training should be based on actual job roles and responsibilities, not on imagined data sets not related to their work. Also, the focus groups indicated that users should be involved in the training from the beginning and that potential users should be assessed before entering internal training sessions. In fact, it seems as if training and data quality could be related, since users might be more comfortable with the data if they understood the content of the warehouse.

\section{Trust and quality}

Although issues like training and the user interface are important to implementation success, why are the dimensions of quality or marketing needs related to quality so important in the implementation of a data warehouse by the marketing function? One possible explanation for the overriding importance of data quality issues in the adoption of the corporate data warehouse comes from social relations theory. The adoption of an information technology system is analogous to a commercial relationship in which trust is a critical element in determining whether partners will enter into and continue in a relationship. ${ }^{22}$ Trust can be defined as a willingness to rely on an exchange partner in whom one has confidence, ${ }^{23}$ in this case another department in the same organisation. That is, to what extent marketing trusts the data provided by the information systems function in the corporate data warehouse will be related to the propensity of marketing to use those data in their daily analysis tasks. Moorman et al. suggest that information supplier and information user relationships influence the extent to which marketing research data are used in decision making. ${ }^{24}$ To this end, well-defined, pre-established relationships with high quality interactions and data quality define the degree of trust in the provider-user relationship.

In fact, Moorman et al. suggest that, although trust and data quality are separate, trust heightens the perception of data quality. Quality appears to signal trust in a system and a willingness to move forward in the relationship, or, in this case, the implementation of the data warehouse. The importance of quality might be heightened in this context in particular because of the competitive pressures in healthcare as they strive to use corporate data to obtain new and retain existing customers. The authors wish to expand the model in the future as seen by the emerging issues identified in Figure 2 to include the trust dimension and to explore further the interrelationship between trust and quality in the context of the adoption of data from the corporate data warehouse for CRM functions.

\section{CASE STUDY CONCLUSIONS}

While this paper complements prior research which suggested data quality is important in CRM implementations, ${ }^{25}$ the authors' work suggests what specific elements of data quality are critical in determining data warehousing implementation success among marketing users. Another contribution of this research is in further identifying the components of an overarching model which can facilitate success in the field of CRM systems supported by a corporate data warehouse. This research can be seen as the first step in understanding the process of how data are used in CRM implementations and how the corporate data warehouse can play a role.

This study indicates that marketing applications must be considered carefully before the data are developed for a corporate data warehouse if marketing is going to use the data. In particular, the 
data and analysis needs of the marketing function were not necessarily consistent with the concept of a corporate data warehouse. Marketing managers have special data needs, such as external data and data about prospects, not just current customers.

These additional data are not always kept in the data warehouse, nor did marketing managers/users accept the quality of the data when they were. Compounding the problem, these users found data warehousing data analysis tools difficult to use. While the users agreed that the data warehouse could have economic benefit, this company discovered, through this research, that data warehousing technologies implemented to meet strategic corporate and IT objectives can be less than successful in the CRM context.

In fact, when the research ended, the company was considering purchasing a separate CRM system using a mini 'data mart' to support marketing applications. This research suggests that data warehousing implementations that fail to adhere to marketing analyses (including data quality) and functional support needs will not gain and sustain the benefits normally associated with these technologies. In sum, the challenge remains for practitioners to migrate data warehousing applications from operational, financial, accounting and production functions to value-added marketing and strategic functions in a meaningful way.

\section{References}

1 Nelson, S. and Eisenfeld, B. (2002) 'Salvaging a failed CRM initiative', Gartner Report SPS-15-4007.

2 Wixom, B. and Watson, H. (2001) 'An empirical investigation of the factors affecting data warehousing success', MIS Quarterly, Vol. 25, No. 1.

3 Wright, L. T., Stone, M. and Abbott, J. (2002) 'The CRM imperative: Practice versus theory in the telecommunications industry', Journal of Database Marketing, Vol. 9, No. 4.

4 Rigby, D. K., Reichheld, F. F. and Schefter, P. (2002) 'Avoid the four perils of CRM', Harvard Business Review, Vol. 80, No. 2.

5 Starkey, M. and Woodcock, N. (2002) 'CRM systems: Necessary but not sufficient. REAP the benefits of customer management', Journal of Database Marketing, Vol. 9, No. 3.

6 CIO Special Advertising Supplement (2001) http://www.idc.com.

7 Nelson and Eisenfeld (2002) op. cit.

8 Woodcock, N. and Starkey, M. (2001) “ "I wouldn't start from here": Finding a way in CRM projects', Journal of Database Marketing, Vol. 9, No. 1.

9 Wixom and Watson (2001) op. cit.

10 Abbott, J., Stone, M. and Buttle, F. (2001) 'Customer relationship management in practice A qualitative study', Journal of Database Marketing, Vol. 9, No. 1.

11 Payton, F. C. and Ginzberg, M. J. (2001) 'Interorganizational health care systems implementations: An exploratory study of early electronic commerce initiatives', Health Care Management Review, Vol. 26, No. 2.

12 Yin, Y. K. (1994) 'Case study research: Design and methods', Applied Social Research Methods Series, Vol. 5, rev. ed., Sage Publications, Newbury Park, CA.

13 Shaw, M. J., Subramaniam, C., Tan, G. W. and Welge, M. E. (2001) 'Knowledge management and data mining for marketing', Decision Support Systems, Vol. 31, No. 1.

14 Jackson, R. and Wang, P. (1995) 'Strategic database marketing', NTC Publishing Group, Lincolnwood, Illinois.

15 Hughes, A. M. (2000) 'Strategic database marketing', McGraw-Hill, New York.

16 Moorman, C., Zaltman, G. and Deshpande, R. (1992) 'Relationships between providers and users of market research: The dynamics of trust within and between organizations', Journal of Marketing Research, Vol. 14, No. 1.

17 Zeithaml, V. A., Parasuraman, A. and Malhotra, A. (2000) 'A conceptual framework for understanding e-service quality: Implications for future research and managerial practice,' Working Paper Report No. 00-115, Marketing Science Institute, Cambridge. MA.

18 Wang, R. Y. and Strong, D. M. (1996) 'What data quality means to data consumers', Journal of Management Information Systems, Vol. 12, No. 4.

19 Ibid.

20 Ibid.

21 Ibid.

22 Morgan, R. M. and Hunt, S. D. (1994) 'The commitment-trust theory of relationship marketing', Journal of Marketing, Vol. 58, No. 3.

23 Moorman et al. (1992) op. cit.

24 Ibid.

25 Abbott et al. (2001) op. cit. 


\section{APPENDIX 1: INTERVIEW GUIDE}

\section{Push/Pull Factors}

1. What economic benefit is your organisation anticipating (has experienced) as a result of data warehouse implementation?

2. Were there any costs to your organisation as a result of participating in this effort? Do (have) the benefits outweigh costs? Explain.

3. How has the competitive environment influenced your decision to implement the data warehouse?

\section{Shared Topology}

4. What types of information will be shared (are shared) among data warehouse users?

5. How (has) will information sharing benefit your organisation?

6. Does the data warehouse provide the precise (eg content), timely, current, relevant and accurate information you need? Does the data warehouse provide quality information to facilitate your needs? If not, what is needed to improve information quality?

7. How has the data warehouse impacted (expected to impact) the quality of the information that you receive (will receive) and use to facilitate decision making?

\section{Behavioural Facilitators}

8. What (has been) will be the role of the internal IT group (vendor)?

9. What types of services/expertise has/should the IT group provided?

10. How has (will) top management been involved in the implementation process?

11. Who are the champions and what are their roles?

12. What end-users are (will be) involved in the data warehouse

implementation process? How was (will be) end-user support gained and assessed?

13. How has (will be) departmental control and autonomy been impacted during the implementation process? 
Understanding why marketing does not use the corporate data warehouse for CRM applications

\section{APPENDIX 2}

Coded items relating to marketing needs, ranked by frequency of mention, major topic, sub-topic

\begin{tabular}{|c|c|c|}
\hline Frequency & Average & Coded item \\
\hline \multicolumn{3}{|c|}{ Ease of use of interface } \\
\hline 15 & 7.5 & Can't meet time frame using CDW currently \\
\hline 14 & 7 & Takes too long for analysis \\
\hline 12 & 6 & Business objects not accessible to all analysts \\
\hline 10 & 5 & Takes too long for requests for changes \\
\hline 10 & 5 & Business objects are easier to use \\
\hline 7 & 3.5 & Executive area can't get answers to marketing questions easily \\
\hline 5 & 2.5 & SQL not accessible to all analysts \\
\hline 3 & 1.5 & Ad hoc queries only, not production of marketing applications \\
\hline 76 & 38 & Total-Ease of use of interface \\
\hline \multicolumn{3}{|c|}{ Ease of use of CDW itself } \\
\hline 54 & 27 & Expect to be able to access data easily \\
\hline 10 & 5 & CDW can't be used to answer basic questions \\
\hline 64 & 32 & Total- Ease of use of CDW itself \\
\hline \multicolumn{3}{|c|}{ Marketing analysis needs } \\
\hline & & Types of analysis that CDW can't perform: \\
\hline 15 & 7.5 & Group characteristics \\
\hline 9 & 4.5 & Contains information only on enrolled groups and members \\
\hline 7 & 3.5 & How many members in each group \\
\hline 4 & 2 & Identifying profitable customers \\
\hline 4 & 2 & Link leads historical data (longitudinal) \\
\hline 4 & 2 & Can't monitor prospects because they are in CDW \\
\hline 3 & 1.5 & Segmentation of offers \\
\hline 3 & 1.5 & Inability to track things longitudinally and across products \\
\hline 3 & 1.5 & $\begin{array}{l}\text { Should identify type of business producer (sales person) has been } \\
\text { selling over time }\end{array}$ \\
\hline 3 & 1.5 & Need to manage customers more effectively and efficiently (analysis) \\
\hline 1 & 0.5 & Differences between customers who purchased and did not \\
\hline 1 & 0.5 & Others \\
\hline 57 & 28.5 & Total-Marketing analysis needs \\
\hline \multicolumn{3}{|c|}{ Need other data in CDW } \\
\hline & 19 & Data not there (Need to gather information) \\
\hline & 19 & Total-Need other data in CDW \\
\hline \multicolumn{3}{|c|}{ Marketing needs not a priority } \\
\hline 21 & 10.5 & Marketing needs not given top priority \\
\hline 10 & 5 & Technical people don't know marketing terms so they can't help us \\
\hline 7 & 3.5 & Marketing lost influence over the warehouse \\
\hline 38 & 19 & Total-Marketing needs not a priority \\
\hline \multicolumn{3}{|c|}{ Lack of trust in system (Quality) } \\
\hline 17 & 8.5 & CDW reports are 'reconciled' to mainframe reports \\
\hline 13 & 6.5 & Mainframe reports are still used, believed in more than CDW \\
\hline 30 & 15 & Total-Lack of trust in system (Quality) \\
\hline \multicolumn{3}{|c|}{ Data dictionary needs } \\
\hline & 8 & Have common definitions \\
\hline 8 & 4 & Need 'data definition sheets' \\
\hline 3 & 1.5 & Expect all data to be in one place \\
\hline 27 & 13.5 & Total-Data dictionary needs \\
\hline \multicolumn{3}{|c|}{ External data needs } \\
\hline 11 & 5.5 & Need demographic data in CDW \\
\hline 9 & 4.5 & Need a marketing 'data universe' \\
\hline 3 & 1.5 & Need Dun \& Bradstreet data in CDW \\
\hline 23 & 11.5 & Total-External data needs \\
\hline \multicolumn{3}{|c|}{ Alternative system needs } \\
\hline & & Other systems that might meet needs: \\
\hline 2 & 1 & Opportunity management (being considered) \\
\hline 1 & 0.5 & Marketing system outside of CDW \\
\hline 3 & 1.5 & Total-Alternative system needs \\
\hline
\end{tabular}

924 total statements coded, 462 per each of two coders 


\section{APPENDIX 3}

Coded items relating to is needs, ranked by frequency of mention, major topic, sub-topic

\begin{tabular}{|c|c|c|}
\hline Frequency & Average & Coded item \\
\hline \multicolumn{3}{|c|}{ Data integration } \\
\hline 49 & 24.5 & Standardisation of data definitions \& structures \\
\hline 1 & 0.5 & Definitions agreed upon over time \\
\hline 50 & 25 & Total-Data integration \\
\hline \multicolumn{3}{|l|}{ Flexibility } \\
\hline 9 & 4.5 & System supports functional elasticity \\
\hline 6 & 3 & Where \& how the CDW must evolve (system flexibility) \\
\hline 10 & 5 & Links architecture, planning, HR skills \\
\hline 25 & 12.5 & Total-Flexibility \\
\hline \multicolumn{3}{|l|}{ Training } \\
\hline 38 & 19 & Training should be based on the actual users roles, job tasks \\
\hline 29 & 14.5 & The training potential of users should be assessed \\
\hline 13 & 6.5 & Tools used to educate users \\
\hline 10 & 5 & Users should be engaged in the training process from the beginning \\
\hline 90 & 45 & Total-Training \\
\hline \multicolumn{3}{|c|}{ Data accuracy } \\
\hline 51 & 25.5 & System provides accurate/right data (as dimension of quality) \\
\hline \multicolumn{3}{|l|}{ Data quality } \\
\hline 18 & 9 & Data that are fit to be used by data consumers a \\
\hline 99 & 49.5 & $\begin{array}{l}\text { Other quality dimensions: Believability, completeness, timeliness, } \\
\text { amount, ease of understanding and accessibility }\end{array}$ \\
\hline 117 & 58.5 & Total-Data quality \\
\hline \multicolumn{3}{|c|}{ Legacy systems } \\
\hline 34 & 17 & Systems used prior to current applications \\
\hline 29 & 14.5 & Legacy systems are vital data sources for CDW \\
\hline 63 & 31.5 & Total-Legacy systems \\
\hline \multicolumn{3}{|c|}{ Needs assessment } \\
\hline 25 & 12.5 & Determination of user requirements \\
\hline 22 & 11 & Communication between work group members, users and managers \\
\hline 16 & 8 & Perceived management support with willingness to commit resources \\
\hline 7 & 3.5 & Strength of management's message re: CDW \\
\hline 70 & 3.5 & Total-Needs assessment \\
\hline \multicolumn{3}{|c|}{ Power user roles } \\
\hline 20 & 10 & Power users have functional jobs and also are gurus for CDW \\
\hline 20 & 10 & Total-Power users \\
\hline \multicolumn{3}{|c|}{ Economic impact } \\
\hline 8 & 4 & $\begin{array}{l}\text { The ability of the application to contribute to perceived economic } \\
\text { benefits }\end{array}$ \\
\hline 5 & 2.5 & Implementing CDW is expensive but nevertheless useful \\
\hline 13 & 6.5 & Total-Economic impact \\
\hline \multicolumn{3}{|c|}{ Top management support: } \\
\hline 13 & 6.5 & $\begin{array}{l}\text { Message is not communicated throughout the company that CDW is } \\
\text { important }\end{array}$ \\
\hline 13 & 6.5 & Top managers don't have time to learn about warehouse \\
\hline 11 & 5.5 & Top managers need to find out what is going on in warehouse \\
\hline 10 & 5 & Top management role not visible \\
\hline 9 & 4.5 & Managers are key to making CDW a success, vendor evaluation \\
\hline 7 & 3.5 & Top management role not clear \\
\hline 3 & 1.5 & Managers came to training session \\
\hline 2 & 1 & $\begin{array}{l}\text { Should have realistic expectation out of warehouse, have better } \\
\text { communication }\end{array}$ \\
\hline 1 & 0.5 & Managers left the training session early; questions importance of CDW \\
\hline 69 & 34.5 & Total-Top management support \\
\hline
\end{tabular}

924 total statements coded, 462 per coder 